\title{
E-learning improves theoretical knowledge on ultrasonography-based assessment of umbilical catheters among pediatricians
}

Kaae R. ${ }^{a}$ Frederiksen C.A. ${ }^{b}$ Kyng KJ. ${ }^{\text {S }} \varnothing r e n s e n ~ J . L .{ }^{c}$ Henriksen T.B. ${ }^{a}$

Background: The efficacy and potential limitations of eLearning for ultrasonography (US) are sparsely investigated

Objective: To assess the improvement in theoretical knowledge and the accuracy of the practical performance following a $1.5 \mathrm{~h}$. eLearning program introducing US based assessment of umbilical catheters

Methods: The study is a comparative observational experiment. The eLearning comprised video examples with voiceover. A 25item multiple-choice questionnaire (MCQ) test was developed and validated. The $M C Q$ was administered before and after eLearning. Twenty one paediatricians with minimal experience in US were included. After eLearning paediatricians performed twelve ultrasonography-examinations in order to assess the catheter placement on piglets with catheters in umbilical vessels on different positions. The theoretical knowledge was measured by the paediatricians' change in the MCQ score.

For the practical learning outcome the sensitivity and specificity of paediatricians ability to assess umbilical catheter placement by the use of US was estimated.

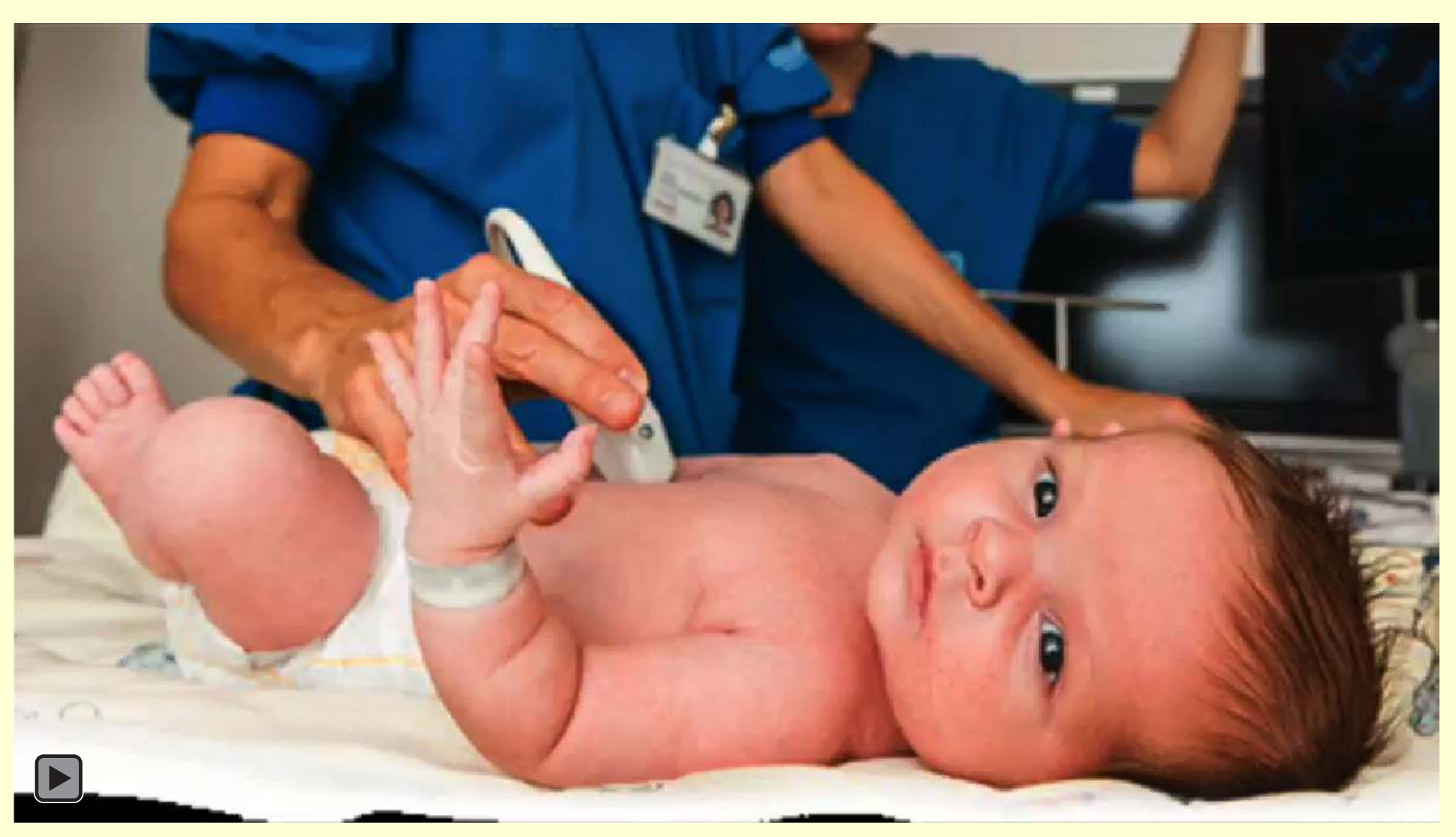

\begin{tabular}{lc} 
Characteristics of participants $\mathrm{n}=21$ & \\
\hline Gender & \\
Female & 16 \\
Male & 5 \\
Level of medical education & \\
Paediatric residents & 12 \\
Paediatricians & 9 \\
Practical experience with US the last year & \\
None & 3 \\
$<1$ per month & 10 \\
$1+$ per month but $<1$ per week & 8 \\
\hline
\end{tabular}

\section{Results: Theoretical learning outcome}

Paediatricians' MCQ scores (mean $\pm S D$ ) before and after completing the eLearning were $161 \pm 30$ and $234 \pm 14$ points, respectively. Mean MCQ score difference was $73 \pm 30$ points $(P<0,0001$, twotailed paired t-test).

Practical learning outcome The paediatricians` ability to detect the umbilical catheter correctly increased with an odds-ratio of $1.6(95 \% \mathrm{Cl} 1.1-2.3)$ and their ability to detect a misplaced catheter increased with an odds-ratio of $3.1(95 \% \mathrm{Cl} 1.8-5.3)$ per $10 \mathrm{~min}$. ultrasound-examination performed. A performance plateau with sensitivity $0.91(95 \% \mathrm{Cl}$ $0.82-0.96)$ and specificity $0.89(95 \% \mathrm{Cl} 0.75-0.95)$ were reached after six ultrasound-examinations.
Conclusion: We found a steep learning curve for paediatricians related targeted US-assessment of umbilical catheter placement. ELearning followed by six 10minutes US-examinations were adequate training. A performance plateau with an accuracy of their ultrasound-examinations that would allow for point-of-care use was achieved.
Learning curves for US based assessment of umbilical catheter placement
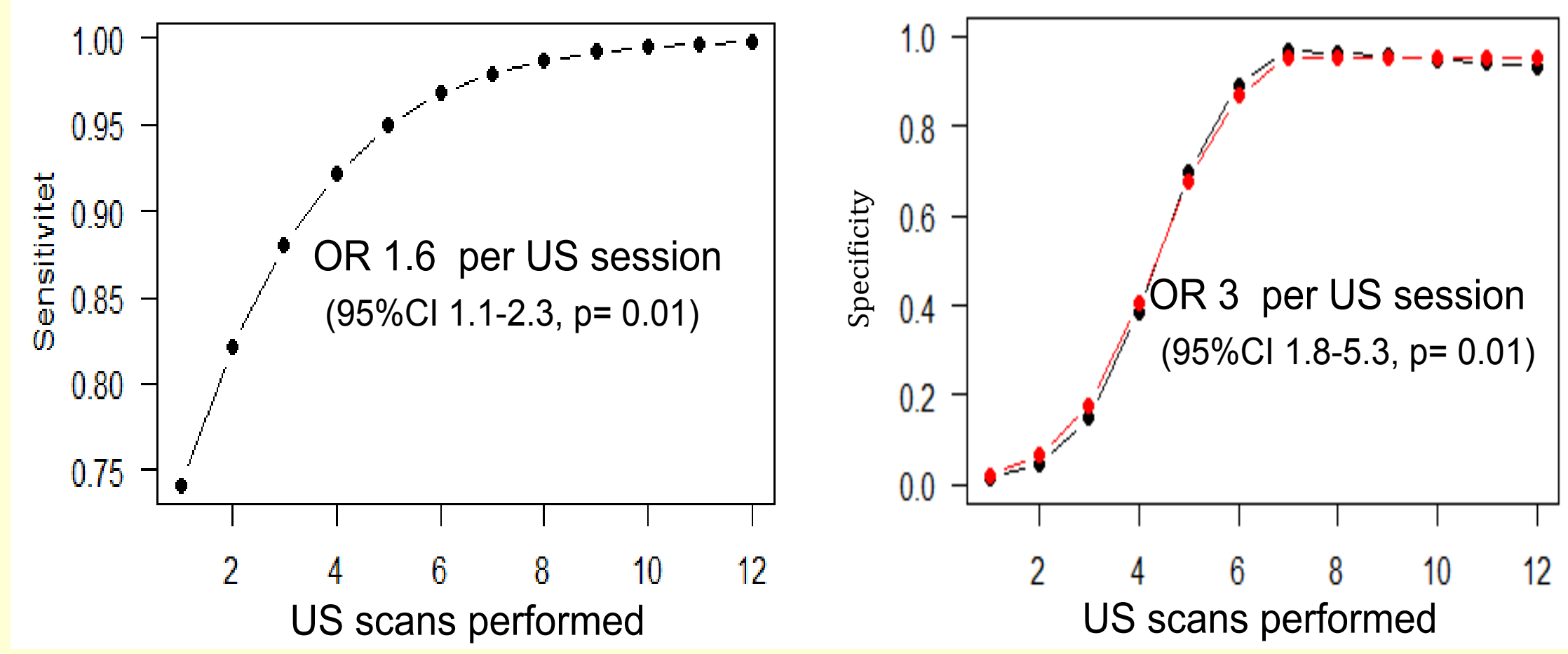
E-mail: Rikkenel@rm.dk 